\title{
El proceso de implantación de la lengua castellana como la única en el Imperio español, a través de la mirada de tres obispos de la segunda mitad del siglo XVIII en Nueva España
}

\author{
Implantation process of the castilian language as the unique one in the Spanish \\ Empire, through the point of view of three bishops in the second half of the \\ eighteenth century in New Spain
}

Isla Citlalli Jiménez Pérez.

Institución: Facultad de Historia de la Universidad Michoacana de San Nicolás de Hidalgo (UMSNH).

islacitla@gmail.com

Fecha de recepción: 23 de julio de 2018

Fecha de aprobación: 20 de enero de 2019

\begin{abstract}
Resumen
Hacia la mitad del siglo XVIII en la Nueva España se hablaba una gran cantidad de lenguas nativas y no únicamente el español o lengua castellana de los conquistadores. El rey, concretamente Carlos III, y el Estado español vieron esa situación de diversidad lingüística como algo peligroso y en contra de sus intereses, por lo que empezaron a promover políticas lingüísticas en contra de las lenguas de los indios, apoyados por arzobispos y obispos, quienes al ser figuras de una importante le darían cauce a ese objetivo.
\end{abstract}

Palabras clave: lengua castellana, lenguas nativas, iglesia católica, políticas lingüísticas.

\begin{abstract}
In the second half of the eighteenth century in the New Spain many languages were spoken, not only the spanish or castilian, the language of the conquerors. The King Charles III, and the Spanish state saw that situation as dangerous and against their interersts, therefore they started to promote language policies to eradicate the native languages, supported by the archbishops and the bishops, important political figures who implemented them.
\end{abstract}

Keywords: castilian language, native languages, catholic church, language policies. 


\section{Introducción}

La lengua castellana, más comúnmente designada como español, tuvo todo un proceso de implantación y consolidación para llegar a ser la más hablada en la Nueva España, en el antiguo Imperio español. Este proceso erróneamente se suele empatar con la conquista y colonización española en América, sin embargo, la gran variedad de lenguas nativas haría esto más complejo. Durante dos siglos y medio el clero regular, conformado por las diferentes órdenes religiosas, apoyaron y defendieron la evangelización y catequesis de los indios en sus lenguas, no obstante, para el siglo XVIII, renace con fuerza el deseo de consolidar la lengua castellana como la única hablada en todo el imperio, lo que se ha denominado como "castellanizar". Esto fue apoyado por el rey, sus ministros, los arzobispos y obispos, en el marco de una monarquía católica donde los prelados de la Iglesia católica tenían peso político y manejaban aspectos de fundamental importancia. Para el caso concreto de México, estos planes de expandir y posicionar a la lengua castellana como la única hablada de norte a sur y de este a oeste tendrían importantes avances hasta el siglo XIX e inicios del XX con los gobiernos liberales y posrevolucionarios, y su impulso a la educación y alfabetización de los indígenas. Este artículo desea acercarse a este proceso de largo aliento de implantación y consolidación de la lengua castellana como la única en la segunda mitad del siglo XVIII, a través de las ideas y acciones de tres influyentes e ilustrados obispos: el arzobispo de México Francisco Antonio Lorenzana y Buitrón, el obispo de Puebla Francisco Fabián y Fuero y el obispo de Michoacán Pedro Anselmo Sánchez de Tagle. Las acciones de estos y otros personajes, en conjunto con la atmósfera de la época, derivaron en la real cédula de 1770 emitida para todas las Indias por el rey Carlos III, que pretendía extinguir las lenguas de los indios, esto será la cima para la época colonial de las ideas en favor del idioma castellano. En las siguientes líneas esbozaremos el panorama general al respecto.

\section{El resurgir ilustrado de la cuestión de la lengua en Imperio español}

Hacia el siglo XVIII, España y sus territorios estaban inmiscuidos dentro de complejos procesos de cambios e importantes coyunturas. Muere en 1700 Carlos II sin descendientes, dando paso a la Guerra de Sucesión, de la cual resulta victorioso Felipe de Anjou de la casa de Borbón, entrando así esta casa reinante a España. Es también la centuria de la Ilustración que permeó en todos los ámbitos, cambia la concepción del poder y de su ejercicio, de la sociedad, de la economía, del arte, de la cultura y de la educación. De este modo, se aprecia el quiebre entre el denominado antiguo régimen, y una sociedad de índole protolibera ${ }^{1}$ hacia la que se transitaba, en donde la razón 
guiaría el pleno desarrollo espiritual y material del ser humano, lo que lo llevaría a las metas por excelencia de la centuria dieciochesca: la felicidad y el progreso ${ }^{2}$. Estas metas tenían una estrecha relación con un nuevo concepto del trabajo, asociado a la producción y la generación de riqueza, en la que era indispensable la participación general de los súbditos, quienes debían ser útiles para alcanzar esos fines.

El mejoramiento material de la sociedad, que generaba progreso y felicidad, fue inmediatamente visto como un fin por el rey y el Estado ${ }^{3}$, quienes, revestidos por el despotismo ilustrado y el regalismo ${ }^{4}$, implementaron diversas disposiciones y políticas ilustradas orientadas al respecto, de las que destacan el bloque de reformas borbónicas, el cual trastocó profundamente distintas esferas. En este contexto se encuentra la secularización de doctrinas de 1749, que en América ameritó el cambio de titularidad de las mismas del clero regular al clero secular, con el fin de que éstos brindaran más lealtad al rey, y además, las constantes quejas del clero secular en contra del regular arguyendo que sus atribuciones y facultades al frente de las parroquias habían sido usurpadas en estos territorios por los regulares ${ }^{5}$. Pues, estos acumularon poder y monopolios materiales e inmateriales, entre ellos la lengua, por haber aprendido las lenguas nativas para evangelizar a los indios, lo que a ojos del siglo XVIII generaba miseria y aislamiento en ese sector de la población, nada benéfico para el progreso anhelado.

Esta marcha y carrera hacia el progreso que impulsaba el Estado abrazaba a todos los sectores sociales, incluyendo a los indios, el sector con más numerosa población $^{6}$ en la Nueva España. Sin embargo, la secularización de doctrinas reacordó que el tema de la unificación lingüística estaba lejos de estar acabado dado la gran cantidad de lenguas nativas que se mantenían y las que en algunos lugares eran la únicas que se hablaban, lo que se veía como un obstáculo para avanzar a las anheladas metas, ya que éstas impedían la comunicación directa y fluida con los indios y por lo mismo, éstos no estaban totalmente integrados a la sociedad, según la perspectiva del rey y sus

La Nueva España en el último tercio del siglo XVIII”, Historia Mexicana, 41.-2 (1991): 167-205.

2 Dorothy Tanck de Estrada, La Ilustración y la educación en la Nueva España (México: SEP, 1985), 11.

3 David Brading lo llama "Nuevo Estado", en: David Brading, Una Iglesia asediada: el obispado de Michoacán, 1749-1810 (México: Fondo de Cultura Económica, 1994), 304.

$4 \quad$ El origen de la palabra proviene de: "De regalía, esto es, derecho del rey.", en: José, M. AndrésGallego, Antón Pazos, La Iglesia en la España contemporánea, 1800-1936, Tomo I, (España: Encuentro Ediciones, 1999), 30. Así, regalismo se refiere al fortalecimiento del poder real dentro y fuera de sus linderos de la figura regia como líder y cabeza de la institución ante la Iglesia católica y el Papa y ante la sociedad, lo que para el caso de España, se acentúa en la segunda mitad de dicha centuria con el rey borbón Carlos III, gran exponente del regalismo y del absolutismo ilustrado.

$5 \quad$ Margarita Menegus, Óscar Mazín et al, La secularización de las doctrinas de indios en la Nueva España. La pugna entre dos iglesias (México, UNAM, 2010), $195 .$.

6 Delfina López Sarrelange, "Población indígena de la Nueva España en el siglo XVIII", Historia Mexicana, 4 (1968). Consultado el día 22 de julio de 2018, http://historiamexicana.colmex.mx/index.php/ RHM/article/view/984, 521. 
ministros. La secularización de doctrinas tiene estrecha relación con las lenguas de los indios y la lengua castellana, ya que, como mencionamos líneas arriba, por dos siglos y medio, desde los inicios de la colonización, las diversas órdenes religiosas se hicieron de las parroquias de indios y aprendieron sus lenguas para evangelizarlos, por lo que el castellano quedó en segundo plano. Al efectuarse la secularización de doctrinas a mediados del siglo XVIII, se remueve a los frailes de las doctrinas de indios y se coloca a un clérigo secular, que generalmente desconocía las diferentes lenguas nativas.

Así, desde la cúspide más alta del poder monárquico, desde el aparato estatal y sus engranajes, así como desde los hombres de letras de la época se impulsó la idea de castellanizar, retomando ideas que venían desde el siglo XV en España con Antonio de Nebrija y su máxima "la lengua es la compañera del imperio", inspirada en el Imperio romano, y su poderío cultural ${ }^{7}$. Es decir, las ideas de castellanización no son endémicas de la centuria dieciochesca, sino que se retoman con renovadas fuerzas. Sobre todo para la segunda mitad del ya referido siglo, con Carlos III a la cabeza del imperio $^{8}$, la cuestión de la lengua castellana reaparece íntimamente relacionada al concepto de comunidad española, de homogeneidad, de bloque, de unificación, de identidad común, de facilitador de la economía, como instrumento político y cultural de barrera a lo invasivo foráneo -esto haciendo alusión a la expansión de Francia y la lengua francesa ${ }^{9}$ - y a un nacionalismo incipiente ${ }^{10}$, que buscaba poner la lengua como un factor de integración, supliendo a la religión católica de tal papel que hasta entonces había llevado. Esto incluía a los indios de la América española, a los cuales era preciso integrar y hacerlos que recibiesen directamente la cultura castellana ${ }^{11}$, y así modificaran sus costumbres y su rol en la sociedad, lo que también le añade un tinte civilizatorio.

$7 \quad$ Eugenio Asensio, "La lengua compañera del imperio. Historia de una idea de Nebrija en España y Portugal”, Filología Española, 43-3 (1960): 401. Antonio Quilis Morales, Hans-Josef Niederehe, The History of Linguistics in Spain, (Ámsterdam: Jhon Benjamins Publishing Company, 1986), 130.

8 Antonio Domínguez Ortiz, Carlos III y la España de la Ilustración, (Madrid: Altaya, 1996), 161-182.

9 Benito Jerónimo Feijoo, uno de los más destacados intelectuales del siglo XVIII en España lamentaba el decaimiento de la lengua castellana comparada con la francesa. Al respecto menciona: "Entre éstos, y aun fuera de éstos, sobresalen algunos apasionados amantes de la lengua Francesa, que prefiriéndola con grandes ventajas a la Castellana, ponderan sus hechizos, exaltan sus primores; y no pudiendo sufrir ni una breve ausencia de su adorado idioma, con algunas voces que usurpan de él, salpican la conversación, aun cuando hablan en Castellano. Esto en parte puede decirse que ya se hizo moda; pues los que hablan Castellano puro, casi son mirados como hombres del tiempo de los Godos.", en: Benito Jerónimo Feijoo, Teatro crítico universal, ó Discursos varios en todo género de materias, para desengaño de errores comunes escrito por el muy ilustre señor Don Fray Benito Gerónimo Feyjoó y Montenegro, Maestro General del Orden de San Benito del Consejo de Su Majestad, tomo primero (Madrid: D. Joaquín Ibarra, Real Compañía de Impresores y Libreros, 1778), $310,311$.

10 Ernest Geller, Naciones y nacionalismo, (España: Alianza editorial, 2001), 185.

11 Humberto Triana y Antorveza, Las lenguas indígenas en el ocaso del Imperio Español, (Chile: Escuela de Filosofía Universal ARCIS, 1993), 12. 
Resulta importante señalar que estos aspectos mencionados dan cuenta de un cambio en la política lingüística que llevaron a cabo los Habsburgo, quienes ya habían tocado estos temas, pero desde otras perspectivas y formas de aplicación. En este sentido, las políticas lingüísticas impulsadas por estos monarcas mantuvieron cierta apertura a las diferentes lenguas de $\operatorname{los}$ indios $^{12}$ y a su uso en diferentes escenarios, ajustándose a esa diversidad. Más aún, en el siglo XVI se buscó por parte de los Habsburgo uniformar la diversidad lingüística mediante las lenguas nativas más habladas -que se denominaron "lenguas generales"-, como el mexicano o náhuatl, y no el castellano, creando también cátedras "públicas" de esas lenguas para que fueran aprendidas por el clero regular y secular ${ }^{13}$. También, resaltan una serie de cédulas reales del siglo XVII en las que la corona española hace énfasis en que se provea a las parroquias de curas y religiosos que dominen las lenguas que habla la feligresía india, insistiendo a los arzobispos y obispos en revisar que esto fuera llevado cabalmente a la práctica ${ }^{14}$. Sin embargo, ya para el siglo XVIII, sobre todo hacia la segunda mitad y con los Borbones en el trono español, se cambia la perspectiva que se había mantenido por dos siglos, al calor de la ilustración, el regalismo, el absolutismo ilustrado, de la desconfianza que generaron diferentes tumultos donde participaron activamente los indios en diferentes puntos de la América española y del nacionalismo.

Así, y volviendo a la centuria dieciochesca, uno de los medios contemplados para llegar a la unificación lingüística era promover la educación en castellano para los indios, denominada como de primeras letras, además, de que el párroco hiciera la explicación de la doctrina cristiana también en castellano. En este sentido, el rey y el Estado se apoyaron en la Iglesia católica para alcanzar tal ideal e implementar sus políticas lingüísticas en ese sentido, lo que fue sencillo gracias a que gran parte del clero español, había sido influenciado por el regalismo, sobre todo el secular a los que se les llamó jansenistas por sus adversarios ${ }^{15}$. Así, el rey, reclamando sus derechos y facultades emanados del Real Patronato ${ }^{16}$, procedió a elegir arzobispos y obispos de

12 Miguel León-Portilla, Independencia, Reforma, Revolución, ¿y los indios qué?, (México: Consejo Nacional para la Cultura y las Artes, Universidad Nacional Autónoma de México, Instituto de Investigaciones Históricas, 2011), 19. Es importante mencionar que estos deseos de unificación lingüística que se retoman con nuevos bríos en el siglo XVIII, también abarcan a la península, que también albergaba numerosas lenguas, como el gallego, catalán, vasco, entre otros. Después de concluida la Guerra de Sucesión, el nuevo monarca en los Decretos de Nueva Planta de 1707-1716, impulsó un sistema jurídico, legislativo, tributario y lingüístico más homogéneo en Valencia, Aragón, Cataluña y Mallorca; así, se estipuló que la lengua castellana tenía carácter oficial en un intento de la corona por centralizar y homogeneizar.

13 Leticia Pérez Puente, "La creación de las cátedras públicas de lenguas indígenas y la secularización parroquial", Estudios de Historia Novohispana, 41, (2009): 45, 55.

14 Nos referimos a las Reales Cédulas de 1603, 1618, 1629, entre otras de importancia para el tema de las parroquias y doctrinas de indios. Véase: Leticia Pérez Puente, El concierto imposible: Los concilios provinciales en la disputa por las parroquias indígenas (México, 1555-1647), (México: UNAM, 2010), . 228243.

15 Richard Herr, España y la revolución del siglo XVIII, (Madrid: Aguilar, 1975), 12.

16 Leticia Pérez Puente, "El obispo. Político de institución divina", en: La Iglesia en la Nueva España. 
carácter regalista, prelados de jerarquía e importancia, que son vistos como figuras de peso y relevancia política, con amplias influencias y posibilidades de cooperación para los fines del Estado y considerados como "[...] ejecutores de sus consideraciones, otorgándoles así un doble carácter: el de prelados diocesanos y el de funcionarios de la monarquía" ${ }^{17}$. Es decir, como agentes del regalismo, del absolutismo ilustrado, del mismo rey y de sus proyectos, como lo fueron, entre otros, el arzobispo de México Francisco Antonio Lorenzana y Buitrón, el obispo de Puebla Francisco Fabián y Fuero y el obispo de Michoacán, Pedro Anselmo Sánchez de Tagle.

\section{Las ideas y proyectos para expandir y consolidar a la lengua castella- na como la única en la Nueva España a través de tres miradas: Méxi- co, Puebla y Michoacán}

\section{- $\quad$ Arzobispado de México}

Comenzaremos mencionando que para la segunda mitad del siglo XVIII el arzobispado de México, el obispado de Puebla y el obispado de Michoacán eran los territorios eclesiásticos más acaudalados de la América hispánica ${ }^{18}$, además, de que eran unos de los más antiguos de toda la Nueva España. En el arzobispado de México, corazón político y eclesiástico del virreinato, gobernó la mitra Francisco Antonio Lorenzana y Buitrón ${ }^{19}$ de 1766 a 1771; este prelado, al igual que los otros dos de los que hablaremos, tenía un carácter regalista e ilustrado ${ }^{20}$ y buscaba que la Iglesia jugara un papel más dinámico en la sociedad y así generar cambios benéficos para el progreso.

Problemas y perspectivas de investigación, coord. María del Pilar Martínez López-Cano (México: Universidad Nacional Autónoma de México, Instituto de Investigaciones Históricas, 2010), 156 - 157.

17 Pérez Puente, "El obispo. Político de institución divina” 159.

18 Oscar Mazín Gómez, “Reorganización del clero secular novohispano en la segunda mitad del siglo XVIII", Relaciones, 39-10 (1989): 75.

19 Francisco Antonio Lorenzana y Buitrón, prelado de origen leonés, fungió como arzobispo de México de 1766 a 1772. Su designio por el monarca Carlos III corresponde como mérito a su labor y trayectoria realizada en España, que se había caracterizado como regalista y jansenista. Su figura es considerada hasta hoy en día por la historiografía como una de las más relevantes de la historia eclesiástica moderna de España, además, del más destacado de la Iglesia hispanoamericana del siglo XVIII, debido a sus acciones al frente del arzobispado de México y por ascender posterior a ello como arzobispo a la sede primada de Toledo, la más rica de España. Lorenzana recibe del palio arzobispal el 8 de septiembre 1766 de manos del obispo de Puebla Francisco Fabián y Fuero (quien había llegado a ocupar el episcopado poblano solo un año antes) su amigo y viejo conocido en España, ya que coincidieron en Sigüenza y Toledo, donde formaron parte de una misma familia eclesiástica. Desde esos momentos previos a su arribo a América, ambos comulgaron en ideas y coincidían en la necesidad de una nueva política que llevara a una reforma eclesiástica, así como en su interés en el estudio y la investigación sobre la historia de la Iglesia, relación que sin duda delinearía el porvenir para esas dos diócesis y para la Nueva España.

20 Juvenal Jaramillo Magaña, Hacia una Iglesia beligerante: La gestión episcopal de Fray Antonio de San Miguel en Michoacán, 1784-1808, los proyectos ilustrados y las defensas canónicas, (Zamora: El Colegio de Michoacán, 1996), 24. 
En este sentido, desde 1767, tan solo un año antes de haber tomado posesión de su mitra, empieza a llamar la atención del rey Carlos III respecto a la cuestión de la lengua y la urgencia de implementar políticas lingüísticas unificadoras.

Lo anterior estuvo en buena parte inspirado en los ruidosos motines y tumultos que se suscitaron en distintos focos de la Nueva España en 1767, resaltando los acaecidos en distintos puntos del obispado de Michoacán, en las localidades de San Luis de la Paz, Cerro de San Pedro, San Luis Potosí, Real de Guadalcázar, San Sebastián Agua del Venado, San Jerónimo de la Hedionda, San Felipe, Guanajuato, Valladolid, Pátzcuaro y Apatzingán ${ }^{21}$, que alarmaron tanto al poder civil y eclesiástico, siendo uno de ellos el arzobispo Lorenzana. Estos agitados y violentos acontecimientos, desde la perspectiva del prelado, tenían una estrecha relación con la diversidad lingüística de la Nueva España, al fraguarse en lo secreto y oculto que facilita el uso de lenguas distintas a la de las autoridades. En algunos de estos puntos donde hubo motines se utilizó como motivo la expulsión de los jesuitas para amotinarse, aunque, todos en conjunto compartían un mismo motivo implícito: el hartazgo de las políticas borbónicas cada vez más radicales. En este sentido, era de esperarse la participación mayoritaria de indios y de castas en los que esas políticas cada vez pesaban más; es decir, ninguno de estos motines fueron monocausales ni únicamente adjudicados a la salida de los jesuitas, sino que hablan de un malestar general.

Grosso modo, estos tumultos en el obispado de Michoacán comparten que en la gran mayoría de ellos hubo importante participación india, tuvieron liderazgos que en algunos casos fue un indio o una india, lograron una unión momentánea, buscaron acercarse a otros pueblos y crear aliados, tuvieron también claras consignas, algunas de ellas en contra del régimen y del rey mismo, expresaron su descontento en manifiestos y sus movimientos se apoyaron y crecieron mediante ejercer violencia directa a las autoridades y a sus edificios ${ }^{22}$. Es cierto, además, que fueron la mayoría de ellos fugaces sin una sólida organización y que fue más causado por el contexto de descontento generalizado. A pesar de su brevedad, estos virulentos episodios en el obispado de Michoacán mostraron lo frágil de las estructuras virreinales, que no solucionaron estos conflictos de manera rápida, sino con mucha dificultad. Fue con la llegada del

21 Para el obispado de Michoacán son diversos los lugares en donde se presentan estos acontecimientos que cada uno merece un tratamiento especial que no daré aquí pero que otros autores con gran erudición se han dedicado a ello. Por ejemplo, en algunos de esos lugares no había jesuitas, pero tenían inconformidades diversas con al reformismo borbónico y hallaron ese momento para manifestarlo. En los lugares donde sí tenía presencia la compañía de Jesús, su expulsión fue solo uno de los factores que catalizaron y propiciaron los tumultos. Para el obispado michoacano recomiendo revisar a Felipe Castro Gutiérrez, Nueva ley y nuevo rey, y a Ofelia Mendoza Briones con su artículo "Pertenencia étnica e interlocución al sistema colonial en Michoacán: 1766 $1767 "$.

22 Véase: Felipe Castro Gutiérrez, Nueva Ley y nuevo Rey: reformas borbónicas y rebelión popular en la Nueva España, (México: El Colegio de Michoacán, Universidad Nacional Autónoma de México, Instituto de Investigaciones Históricas, 1996), 288 . 
visitador José de Gálvez que los principales motines del obispado michoacano fueron suprimidos con severidad, dejando un saldo total de 85 hombres ahorcados, 73 azotados, 117 desterrados y sentenció a 674 a diversos periodos de prisión ${ }^{23}$.

No obstante, a pesar del ejemplar castigo a los insurrectos, el miedo y el temor había permeado en las conciencias. El arzobispo Lorenzana es un claro ejemplo de ello. De este modo, estas rebeliones sirvieron de aliciente para el comienzo de una campaña directa en contra de las lenguas nativas, como facilitadoras del desorden, la sedición y la conspiración en contra de la figura y el aparato real, impulsada por el Lorenzana quién argüía en 1769, en una carta pastoral que "el mantener el idioma de los indios es [...] mantener en el pecho una ascua de fuego un fomento de discordia y una piedra de escándalo, para que se miren con aversión entre sí los vasallos de un mismo soberano" 24

En este sentido, como arzobispo de México, puso especial atención al tema de la lengua, siendo, desde mi punto de vista, uno de los ejes rectores de su gestión arzobispal. Hacia 1767, en el marco de la primera visita pastoral que llevó a cabo en su arquidiócesis, se encontraba en la población de Huazalingo, donde el arzobispo Lorenzana: “[...] hizo una breve plática en que manifestó a los naturales el gran consuelo que había recibido de oir (sic) cantar a los indios la Doctrina en castellano, ponderándoles lo innumerables bienes que de esto se siguen así en lo temporal como en lo espiritual[...]"25.

Posteriormente visitó el rancho de Zinacatipam, jurisdicción de Huaiacocotla, donde el prelado reforzó lo anteriormente dicho en Huazalingo, añadiendo la importancia que tenía que los niños aprendieran a rezar en castellano la doctrina cristiana, lo que nos habla del especial enfoque que se tenía para la niñez como la que enmendaría lo hecho en el pasado. Para el día 18 de la sexta visita en 1769 en Chimalhuacán Lorenzana "[...]predicó exhortando a los indios a que aprehendiesen (sic) el castellano, por haberlos hallado muy cerrados en su idioma. ${ }^{26 "}$

Así mismo, "durante sus visitas pastorales le dio tal importancia al tema del idioma castellano que donde encontró la existencia de escuelas nombró maestros o les otorgó sus respectivas licencias. Así por ejemplo, en la villa de Santiago de los Valles

23 Omar Guerrero, Las raíces borbónicas del estado mexicano, (México: Universidad Nacional Autónoma de México, 1994), 158.

24 Dorothy Tanck de Estrada, "El siglo de las luces", en: Independencia y Educación. Cultura cívica, educación indígena y literatura infantil, coord. Dorothy Thanck de Estrada (México: El Colegio de México, 2013), 128.

25 Clemente Cruz Peralta, "Entre la disciplina eclesiástica y la reforma de las costumbres: Visitas pastorales de Francisco Antonio Lorenzana a la arquidiócesis de México, 1767-1769”, (Tesis de maestría, Universidad Nacional Autónoma de México, Facultad de Filosofía y Letras, Instituto de Investigaciones Históricas, 2016), 264.

26 Peralta, "Entre la disciplina eclesiástica”, 270, 405. 
expidió el título de maestro de primera letras a don Juan Joaquín de Villasana [...]"27 Esto demuestra el interés del prelado en continuar con el proyecto de castellanización y de fundación de escuelas de primeras letras para los indios, que le habían legado sus antecesores. Allí se reafirmó una estructura dual de la enseñanza del castellano a los indios, que por un lado recaía en el párroco y en la doctrina cristiana, y por el otro, en el maestro de primeras letras en las escuelas, justificando su establecimiento "por 'los aumentos que de esto se siguen para el buen gobierno y régimen de las repúblicas' de indios" 28 .

En esa misma línea, el arzobispo Lorenzana en 1768 dedica una carta pastoral al tema de los indios y los medios que desde su perspectiva serían los mejores para sacudirse la pobreza y marginación que vivían. Estas pastorales las tituló: Reglas para que los Naturales de estos Reynos sean felices en lo espiritual y temporal, en las cuales, según su juicio, "está todo el nervio, y substancia de la prosperidad nacional". Llama la atención que la primera de estas reglas esté relacionada con la lengua castellana y su relación con el "orden", la cual refiere explícitamente lo siguiente:

"Primera: Que guarden el santo temor de Dios: Sepan la Doctrina Christiana, no solo en su Idioma, sino principalmente en Castellano; cuiden de educar bien sus hijos; respeten á sus Superiores, sean obedientes á los Parrocos, y Justicias, pues sin esto todo será desorden." ${ }^{29}$

También, entre estas reglas pensadas por Lorenzana se incluyen otras de carácter civilizatorio, como por ejemplo cambiar las costumbres de los indios hacia otras más occidentalizadas, lo que nos acerca a la visión del arzobispo sobre los indios y sus culturas, connotadas como "bárbaras" y "salvajes", además, se les exhortaba al trabajo para acercarlos a la felicidad y progreso común:

"Tercera: No permitan los Gobernadores, que Indio alguno de mas de veinte y cinco años, dexe de tener Oficio en el Pueblo, sea de Labrador, ó Jornalero, y que luego, que se casen, fabríquen su Casa, ó Xacal, procurando en esto ayudarse unos á otros, y assi les costará muy poco: Como tambien cuidarán de que los Xacales se hagan como para racionales, y no para bestias $\square \ldots \square$ y procurando, que todos haviten en Poblacion cerca de su Iglesia, ó á lo menos no muy distante; pues se sigue mucho perjuicio para sus Almas, y cuerpos, quedando enteramente desamparados de socorro, espiritual, y temporal, y expuestos en los Montes, y soledad a incurrir en pecados, supersticiones, é idolatrías." ${ }^{30}$

27 Peralta, "Entre la disciplina eclesiástica", 173.

28 Peralta, "Entre la disciplina eclesiástica", 174.

29 Francisco Antonio Lorenzana, Reglas Para que los Naturales de estos Reynos sean felices en lo espiritual, y temporal, (México: 1768), SNP, http://bdh.bne.es/bnesearch/detalle/bdh0000038591 .

30 Lorenzana, Reglas Para que los Naturales de estos Reynos sean felices en lo espiritual, y temporal. 
El proceso de implantación de la lengua castellana como la única en el Imperio español,

Claramente, para Francisco Antonio Lorenzana que los indios supieran el castellano tendría que apoyarse de las escuelas de primeras letras y no solo de la catequesis parroquial. Afianzando lo ya realizado en sus visitas pastorales y en la novena regla estipuló:

"Nona: Que tengan Escuela de Castellano, y aprehendan los niños á leer, y escribir, pues de este modo adelantarán, sabrán cuidar su casa, podrán ser Oficiales de Republica, y explicarse con sus Superiores, ennobleciendo su Nacion, y desterrando la ignorancia, que tienen, no solo de los Mysterios de la Fé, sino tambien del modo de cultivar sus tierras, cria de ganados, y comercio de sus frutos, á lo que se añade ser falta de respeto hablar en su Idioma con los Superiores, ó delante de ellos, pudiendo hacerlo en Castellano, aunque sea hablando poco." 31

Esta marcada tendencia y postura no era exclusiva del arzobispo Lorenzana, había toda una corriente de prelados, antecesores -el arzobispo Manuel Rubio y Salinas ${ }^{32}$ para él- y contemporáneos que planteaban postulados semejantes en torno a la lengua, los indios, la enseñanza de las primeras letras y de la doctrina en castellano, sin embargo, es para la segunda mitad del siglo XVIII que estas retoman una mayor fuerza.

\section{- Obispado de Puebla}

Francisco Fabián y Fuero se desempeñó como obispo de Puebla de 1765 a 1773. Con el arzobispo Lorenzana había creado desde España una mancuerna de ideas muy importante y crucial para su posterior actuar en Nueva España ${ }^{33}$. Uno de sus puntos

31 Francisco Antonio Lorenzana, Reglas Para que los Naturales de estos Reynos sean felices en lo espiritual, y temporal, SNP.

32 Dorothy Tanck de Estrada, "Castellanización política y escuelas de indios en el Arzobispado de México a mediados del siglo XVIII", Historia Mexicana, 38-4 (1989): 706.

33 El Doctor Francisco Fabián y Fuero llegó a la mitra poblana en el año de 1765 procedente de España donde había comenzado la construcción de una fecunda carrera eclesiástica que ya empezaba a dar sus frutos. Uno de ellos, sin duda, era su designio como obispo de Puebla. En España fincó su carrera en distintos centros de estudio, destacando por pertenecer a la corriente de reformismo eclesiástico, modernidad cristiana e ilustración católica, logrando escalar en la pirámide eclesial, apoyado por un grupo, o familia eclesiástica como lo han llamado algunos estudiosos, que se formó en la ciudad de Toledo, la sede episcopal más rica de España. Este grupo fundó una Academia de Historia Eclesiástica, interesados por la historia primitiva de la Iglesia y los estudios bíblicos. Entre este grupo sobresale la mancuerna en ideas y acciones que hicieron desde España, primero en Sigüenza y después en el obispado de Toledo donde confluyeron, Fabián y Fuero y Francisco Antonio de Lorenzana y Buitrón, quien será el arzobispo de México contemporáneo a él; es decir, cada uno posicionado en los dos territorios eclesiásticos más ricos de todo el Imperio español en América desde donde se propusieron impulsar una reforma eclesiástica que brindara renovación y solución a problemáticas sin resolver, causa en la que ya habían avocado sus esfuerzos en España. 
de encuentro era que ambos estaban "en contra del idioma indígena como "escaso y bárbaro' y más parecido a 'mugidos de bestias que articulación de racionales" 34 .

En el obispo Fabián y Fuero también permeó el temor de otra rebelión donde participaran los indios como las ocurridas en 1767. En este sentido, los documentos que legó denotan su carácter regalista y la preocupación por los murmullos facilitados por el común uso de otras lenguas que no el castellano que propiciaban los secretos, la clandestinidad, la sedición y la diversidad de opiniones en un territorio en donde solo tenía que valer una única opinión, la del Rey. Ya decía en su carta pastoral de 1767:

"Recompensar al Rey lo que trabaja, y se desvela por nosotros, enseñando á los Pueblos de que cuidamos Fidelidad y Obediencia, y dedicandonos con esmero á los demás ministerios espirituales, ese es nuestro oficio. Oygan todos de nuestras bocas, que no pertenece á los Vasallos averiguar el porqué de lo que manda su Soberano, sino atender, y obedecer lo que ordena. Una gran parte del saber es ignorar ciertas cosas: no mas saber, que lo que conviene saber; porque no ha sujetado Dios el corazon del Rey á nuestros escrutinios. Quando con el semblante no podamos hacer callar la lengua murmuradora, mostrando rostro triste y desapacible, oygan todos de nuestros labios, que es contra lo mandado por Dios el decir mal del Rey." ${ }^{35}$

Es posible que Fabián y Fuero dedicara estos argumentos a los célebres y ya referidos tumultos y motines ocurridos en 1767 en distintos espacios del obispado de Michoacán, eventos que a mi juicio radicalizan las posturas lingüísticas y apuran los esfuerzos para generar un cambio, ya que se considera a las lenguas nativas como una amenaza ${ }^{36}$.

Lo anterior refrendará y funge como antesala de lo que sería uno de los documentos y actitudes más decisivas en aspectos de política lingüística en la Nueva España, otra carta pastoral de su autoría publicada solo un año después, el 19 de octubre de $1769^{37}$ titulada: Pastoral de Don Francisco Fabián y Fuero, obispo de Puebla, a los

$34 \quad$ Tanck de Estrada, Dorothy, "Castellanización política y escuelas de indios", 729.

35 Francisco Fabián y Fuero, Carta pastoral del Ilustrísimo Señor Don Francisco Fabián y Fuero, Obispo de la Puebla de los Ángeles, Del consejo de su majestad, (Barcelona: Thomas Piferrer Impresor del Rey Nuestro Señor, 1768), 34, http://www.cervantesvirtual.com/obras/materia/cartas-pastorales-287.

36 El arzobispo de México Francisco Antonio de Lorenzana mantuvo una radical y definida postura respecto a brindar la connotación de amenaza a las lenguas nativas. Eran amenazas que trascendían lo local y se volvieron un asunto de toda importancia para el imperio. Sin duda esta visión de Lorenzana halló eco no solo en el rey sino también en su amigo Fabián y Fuero, por entonces obispo de Puebla. Véase: Tanck de Estrada, Dorothy, "Castellanización, política y escuelas de indios", 728.

37 Esta pastoral recoge muchas ideas, algunas de ellas textuales, que el prelado emitió en un edicto de un mes anterior, con fecha de 19 de septiembre de 1769, titulado: Francisco Fabián y Fuero, Edicto para que los Curas expliquen y enseñen Castellano por Sí, y por sus Ministros la Doctrina Christiana á todos los Naturales, y cuiden de que Estos hablen igualmente en Castellano las cosas del trato comun, ó vulgares. Véase: Fabián y Fuero, Francisco, Colección de Providencias Diocesanas de la Puebla de los Ángeles, (Puebla: Imprenta del 
curas de su diócesis ordenándoles usen el castellano, por ser insuficientes las lenguas aborígenes y contar la diócesis con 250 años de vida cristiana. El saber idiomas no será mérito para obtención de parroquias, y sí poseer buena formación cultural. En esta carta pastoral la castellanización de los indios hallaba justificantes en diversos argumentos, como los históricos, al hablar de los doscientos cincuenta años que ya han pasado de la conquista y de que la mayoría de los indios comprendían y hablaban el castellano, además, de argumentos de índole neocolonial/colonialistas, sobre ejercer una dominación, incluso imposición, más efectiva y directa sobre los indios en el tema de la lengua, subrayando su papel como conquistados, además de desacreditarlas lenguas nativas. Decía el prelado textualmente:

"En consideración asimismo de que los indios desde que fueron conquistados por nuestros católicos monarcas, no tienen derecho alguno de justicias que se le mantengan sus lenguas, antes sí lo gozan nuestros Soberanos de hacer valer la suya en la vasta extensión de sus dominios, para que siendo todas sus tierras de un solo labio y de unas mismas palabras, las puedan gobernar más fácil y uniformemente, y más cuando entre todas las lenguas de los naturales, aún inclusa la mexicana que es la más abundante, ninguna se puede llamar sabia [...]"38

Para el obispo Fabián y Fuero el mantener los diferentes idiomas de los indios tenía consecuencias negativas para el Estado y la religión, siendo el argumento religioso y de comprensión del dogma uno de los que perdurarán en el discurso castellanizador, o dicho en otras palabras en lo temporal y espiritual. También, mencionaba que el darles continuidad: “[...] es causa de que estén menos instruidos, no sólo en lo civil, si también en la doctrina cristiana. Y consiguientemente el que cierra en ello influye, aunque sin pensar, en los impedimentos de la salvación de los indios, porque les hace ser más tenaces de sus antiguos abusos, contemplándose maquinalmente con esto como separados de los demás vasallos" ${ }^{\prime 3}$.

El mitrado también condena la postura de los indios de defensa a sus lenguas aun sabiendo castellano, lo que según su óptica va en contra de la conquista, su papel como conquistados y las instituciones coloniales. Finalmente, el obispo Fabián y Fuero se apoya en lo dictado a favor de la castellanización por la Recopilación de leyes de indias para disuadir también a los indios de que aprendieran la lengua castellana, lo que llevaba a otros beneficios de gobierno y políticos. Decía el prelado: "Hacemos saber a todos los naturales para que no vivan engañados, que aunque todos lleguen a entender y hablar el castellano, nunca se quedarán sin ser gobernantes, alcaldes y prin-

Real Seminario Palafoxiano, 1770), 115- 124, http://bdh.bne.es/bnesearch/Search.do? .

38 Francisco de Solano (comp.), Documentos sobre política lingüistica en Hispanoamérica (1492-1800), (Madrid: Consejo Superior de Investigaciones Científicas, 1991), 247.

39 De Solano, Documentos sobre política lingüistica, 248. 
cipales de república, antes bien se pondrán así más proporcionados para serlo, y para que el Rey nuestro señor les haga más mercedes" ${ }^{40}$.El obispo refuerza lo dicho ahora con argumentos referentes a la buena conducta y al deber de los indios de agradar y evitar dificultades a sus superiores a través de la lengua castellana, ya que "[...] no es descortesía hablar [...] en castellano a los padres y demás superiores [...] por que a cada superior se la ha de procurar hablar en su nativo idioma para darle más gusto con el rendimiento de que se pone en la mira en imitarle [...] y que no quiere darle trabajo, sí mucho obsequio y placer" ${ }^{41}$.

El mitrado remata su carta pastoral exhortando al clero a enseñar a los indios el castellano, apoyándose de maestros, y explicar la doctrina cristiana en el mismo idioma comprendiendo cabeceras, barrios, pueblos y haciendas para esto. También se supervisaría por los clérigos el uso del castellano en la cotidianeidad de las diferentes actividades de los indios, "[...] a fin de que con la ejecución de todo lo referido les vean respetadas y obedecidas las leyes y se dé principio a desterrar una preocupación, que aunque hasta ahora ha obrado en muchos de buena fe es sumamente perjudicial a la religión y al estado [...]"42. Esta carta pastoral donde plasmó sus ideas al respecto el obispo de Puebla Francisco Fabián y Fuero es una de las más importantes para la castellanización en la Nueva España.

\section{- Obispado de Michoacán}

Pedro Anselmo Sánchez de Tagle ${ }^{43}$ fue obispo de Michoacán de 1758 a 1772. Es justamente a él a quién le toca enfrentar los momentos de mayor tensión debido a la resistencia de algunas órdenes religiosas de secularizar sus parroquias y todo el poder material e inmaterial que habían acumulado históricamente, además, de los ya citados motines de 1767 que tuvieron lugar en diferentes puntos de la diócesis. Volviendo al tema de la secularización de doctrinas, para este momento se intensificaron los roces

$40 \quad$ De Solano, Documentos sobre política lingüistica, 249.

41 De Solano, Documentos sobre politica lingüistica, 249.

42 De Solano, Documentos sobre política lingüística, 249.

43 El obispo Pedro Anselmo Sánchez de Tagle llegó a ocupar la diócesis michoacana en el año de 1758, prolongando su prelatura hasta el año de 1772 cuando lo alcanzó su muerte. Originario de Santillana, España, miembro de una hidalga familia con una estrecha relación con América, estudió en la universidad de Valladolid, de ahí pasó a Salamanca recibiendo el grado de doctor por la capilla de Santa Bárbara. Tagle consagró su carrera eclesiástica en la Nueva España, primero como inquisidor mayor del Tribunal de la Inquisición, luego como obispo de Durango, y posteriormente de Michoacán donde enfrentó diversos momentos de cambio muy significativos para el futuro no solo de su diócesis, sino de todo el virreinato; nos referimos, esencialmente, a las reformas borbónicas aplicadas por el rey Carlos III que para la segunda mitad de la centuria dieciochesca se recrudecen generando diferentes reacciones en la sociedad novohispana. Entre estas estuvieron la secularización de doctrinas, la expulsión de los jesuitas en 1767, así como la visita de José de Gálvez, entre otras. Por la historiografía posterior, se ha catalogado a Sánchez de Tagle como parte de la corriente de pensamiento de proto-ilustración o ilustración mexicana. 
del obispo Sánchez de Tagle con las órdenes religiosas y también con el virrey Cruillas que en algunos momentos obvió sus opiniones. Sobre todo, los conventos de la diócesis michoacana que más causaron conflicto y polémica fueron los agustinos de Charo, Ucareo y Yuriria, llegando sus alegatos hasta Madrid y Roma, obteniendo suavizar la secularización ${ }^{44}$. Otros brotes de enconado conflicto fueron con los franciscanos de Zitácuaro y en Celaya. Al final, el saldo para la gestión episcopal de Sánchez de Tagle fue "De las 25 doctrinas agustinianas, 16 pasaron al clero secular entre 1758 y 1772. Y de las 36 franciscanas, por lo menos 26 fueron secularizadas por los mismos años"45

Este decidido impulso a la secularización de doctrinas del obispo Pedro Anselmo Sánchez de Tagle sacó de nuevo a flote el tema acerca del idioma en el que se administrarían los sacramentos a la feligresía india de esas parroquias, las cuales ya estaban en manos del clero secular. En general en el obispado de Michoacán, y en el virreinato, las órdenes religiosas se habían caracterizado a lo largo de los siglos coloniales como impulsoras de la catequesis en los diferentes idiomas de los indios ${ }^{46}$, algunos de ellos enfocándose con gran dedicación y erudición a hacer tratados de las diferentes lenguas que se hablaban en la Nueva España.

En este sentido, y según algunos estudios, la secularización de doctrinas impulsó un cambio del modelo de enseñanza ${ }^{47}$ de primeras letras que se había seguido en el obispado de Michoacán entre los años de 1765 y 1767, además, de poner como protagonista de ese cambio al racionero del cabildo eclesiástico de Valladolid, Gerónimo López Llergo, quién se encargó de llevarlo a cabo por mandato directo del obispo Pedro Anselmo Sánchez de Tagle, quien fungía como su mano derecha en la puesta en marcha de este nuevo modelo educativo. Así pues, la gestión episcopal de Sánchez de Tagle se caracterizó por el impulso a la castellanización y a la enseñanza elemental para los indios también en lengua castellana en escuelas parroquiales ${ }^{48}$ implantadas,

44 Mazín, "Secularización de parroquias en el antiguo Michoacán”, Relaciones 26.4, (1986): 31.

45 Mazín, "Secularización de parroquias en el antiguo Michoacán", 32.

46 Blanca Estela Aranda Juárez, "La educación en los religiosos agustinos del siglo XVII", Destiempos 18 (2009). Consultado el 3 de mayo, http://www.destiempos.com/n18/aranda.pdf, 150.

47 Para el caso concreto del obispado de Michoacán, las investigaciones han arrojado la existencia de por lo menos cuatro modelos de educación elemental durante la época virreinal, desde el siglo XVI al XVIII: las escuelas de doctrina, las escuelas de castellano, las escuelas parroquiales y las escuelas de cajas de comunidad: en María Guadalupe Cedeño Peguero, "Las escuelas parroquiales del obispado de Michoacán, Nueva España, Reforma educativa de Gerónimo López Llergo, 1765-17670", Heurística Revista Digital de Historia de la Educación 17 (2014), consultado el día 15 de mayo de 2018, https://dialnet.unirioja.es/servlet/ revista? codigo $=11336,248-251$.

48 Éste es el término con el que las designa Guadalupe Cedeño Peguero que menciona en su trabajo: "Desde mi perspectiva, estas escuelas merecen este nombre porque fue el párroco protagonista durante todo su funcionamiento; dichas instituciones serán fundadas por ellos, y será obligación de éstos que en ellas se imparta la doctrina, pero también las primeras letras, las cuales - a partir de este periodo - también estarán bajo su cuidado administrativo, directivo y académico. En ellas se separan los aprendizajes de la doctrina y las primeras letras y ambas se enseñan a los alumnos por separación de sexos [...] asimismo, se buscan un tipo especial de maestro para cada uno de los nuevos rubros que surgen: preceptor para los varones, y maestra para las niñas, 
impulsadas, ordenadas y reglamentadas por López Llergo ${ }^{49}$, que luego transitarían a las de primeras letras sostenidas por las cajas de comunidad de los pueblos de indios.

En este contexto, en 1765, el obispo Sánchez de Tagle envió a López Llergo a realizar una visita a la región norte del obispado donde:

“[...] una de las finalidades de la revisión fue la promoción de creación de escuelas parroquiales, se puede constatar el avance del proceso de incremento parroquial. De las misiones revisadas por este último visitador: Valle del Maíz, Valle de Piningüan, San Antonio Tula y San Miguel de los infantes, algunas ya funcionaban como parroquias con su centro escolar, y [...] éstas no sólo castellanizaban sino también alfabetizaban" 50

Gerónimo López Llergo se distinguió por promover las escuelas parroquiales en otros lugares del vasto obispado ${ }^{51}$, lo que deja ver que este fue un proyecto educativo formal del obispo, siendo López Llergo el encargado de organizarlo y estructurarlo ${ }^{52}$. La diferenciación de éste proyecto educativo a los anteriores que habían existido en la diócesis michoacana radica en lo siguiente:

"Las escuelas del clero secular no eran cosa nueva en Michoacán, pues habían sido impulsadas desde las administraciones de Marcos Ramírez del Prado (1640-1666) y Juan Ortega y Montañés (1682-1700); pero esas versiones escolares se habían centrado en la promoción de la enseñanza de la doctrina en castellano, sin haberse ocupado de la enseñanza de las primeras letras. En cambio, las impulsadas por López de Llergo, además de la enseñanza religiosa, se proponía impartir la lectura y la escritura de una forma generalizada, para hacer posible el acceso a la alfabetización a todos los niños del obispado, en especial a los indígenas pobres $[\ldots]^{\prime \prime 53}$

Es justamente la separación de la enseñanza de primeras letras y de la doctrina cristiana, además, de que en la primera estaría a cargo de un maestro seglar ${ }^{54}$ y en la

maestro de doctrina o doctrinero para los hombres e igual para las mujeres, pero de sexo femenino. ". Véase: Cedeño Peguero, "Las escuelas parroquiales", 250.

49 Cedeño Peguero, "Las escuelas parroquiales", 248.

50 Cedeño Peguero, "Educación, iglesia y estado. De las escuelas de castellano a las de caja de comunidad. Tres momentos de la educación elemental indígena en el Michoacán colonial. Siglos XVII y XVIII", (Tesis de doctorado, UNAM, 2011), 189.

51 Cedeño Peguero, "Educación, iglesia y estado", 197.

52 Cedeño Peguero, "Educación, iglesia y estado", 197.

53 Cedeño Peguero, "Educación, iglesia y estado", 197.

54 Guadalupe Cedeño Peguero menciona: "Es importante aclarar que es en este momento y como una forma de avanzar en la secularización de las costumbres, que se limita la función de los indios e indias como maestros para sustituirlos por sus homólogos españoles, mestizos o incluso de alguna casta, antes de permitírseles a los naturales seguir ocupando este oficio; y es que, precisamente, puestos por los regulares por el importantísimo y fundamental apoyo que significaron para ellos, fueron identificados con éstos como ligados 
segunda del párroco, lo que diferencia la política educativa del obispo Sánchez de Tagle. Cabe resaltar que tanto la educación de primeras letras y la de la doctrina cristiana se haría en lengua castellana. De este modo, este nuevo modelo educativo es diseñado por el obispo de modo que apoyará la secularización de doctrinas y así desquebrajar el antiguo modelo regular de administración de las parroquias y de enseñanza de la doctrina cristiana en lenguas nativas. Es decir, además de integrar al indio a su sociedad, este modelo buscaba crear uno nuevo en que la herencia de las órdenes religiosas se anulara.

Estos decididos esfuerzos de fundación de escuelas de primeras letras en lengua castellana también llevaron al obispo Sánchez de Tagle a fundar una escuela de ese tipo en 1770, el recién fundado Seminario Tridentino localizado en Valladolid (hoy Morelia), la capital del obispado michoacano, lo que refrenda el interés del obispo de mejorar la educación de los infantes y su educación elemental ${ }^{55}$. Esta escuela admitiría:"[...] qualesquiera niños, que â ella ocurran, ó lleven sus Padres, sean pobres ó ricos; pero precisamente han de ser Españoles, ó Indios puros, ó mistos de Indio y Español; y no Mulatos, Lobos, Negros, Chinos, ni otras castas"

También, se señala por parte del obispo que ni los niños ni sus familias tendrían que pagar por esta enseñanza; además, se señala que el maestro tendría que estar nombrado directamente por el obispo, ser español y "persona piadosa de buena vida, y costumbres, de quien se espere, que sembrará las primeras semillas de piedad en los corazones de sus discípulos" 57 . Estos esfuerzos del obispo se continuaron por otros prelados aún después de su muerte, dando un importante paso en la fundación de escuelas de primeras letras para los indios.

\section{La real cédula de 1770 y la cima de las políticas castellanizadoras}

Estas acciones de estos prelados no fueron aisladas. En todo el Imperio español había manifestaciones y acciones de este tipo con sus peculiaridades. Era un aire común que se respiraba desde las más altas esferas del poder y motivado también por las mismas. En este sentido, el rey Carlos III, en parte por la decidida injerencia del arzobispo Lorenzana sobre el tema, emitió el 16 de abril de 1770 la "Real cédula para

al viejo paradigma doctrinal de los primeros tiempos.” En: María Guadalupe Cedeño Peguero, "Las escuelas parroquiales", 251.

55 El obispo Sánchez de Tagle señala en las constituciones del seminario: “La enseñanza de las primeras letras, ó la Instruccion de los Jovenes en las Artes de leer, escribir, y contar, es de la mayor necesidad, como que hace lastima, el veer Sujetos, despues de muchos años de Estudios, y de haver hecho en ellos considerables progre os (sic), cometer gorseras faltas en la locucion, y Escritura, por el poco cuidado, que se úso en formarlos â tiempo.", en: Agustín García Alcaraz, La cuna ideológica de la independencia, (Morelia: Fimax publicistas, 1971), 220.

56 García Alcaraz, La cuna ideológica de la independencia, 221.

57 García Alcaraz, La cuna ideológica de la independencia, 220-221. 
que en los reinos de las Indias se extingan los diferentes idiomas de que se usa y sólo se hable el castellano", cédula de contundente nombre que abona sustancialmente esta oleada de esfuerzos y políticas lingüísticas a favor de la lengua castellana ${ }^{58}$. Llama mucho la atención de que en el título de esta cédula está integrado el verbo "extinguir", lo que dice mucho de las intenciones predominantes respecto a las lenguas nativas, además, de que al hablar de las Indias, no sólo se refiere a la Nueva España, sino a toda la América y Asia hispánica, lo que le da más relieve e impacto a la cédula.

En ésta cédula se ratifica la enseñanza de los indios a leer y escribir en castellano en las escuelas así como la doctrina cristiana, así mismo el castellano tiene implicaciones religiosas y sociales "[...] este idioma que se debe extender y hacer único y universal en los mismos dominios, por ser el propio de los monarcas y conquistadores, para facilitar la administración y pasto espiritual a los naturales y que éstos puedan ser entendidos de los superiores, tomen amor a la nación conquistadora, destierren la idolatría, se civilicen para el trato y el comercio." 59 . Sin embargo, con pesar el rey Carlos III refiere los inconvenientes que estas políticas impulsadas por él y sus predecesores se han encontrado, comenzando por los indios que:

“están cerrados, rehusando aprehender el castellano y el enviar sus hijos a la escuela $[\ldots]$ al cura y vicarios nunca les hablan en castellano; sucediendo lo mismo con los alcaldes mayores y justicias, valiéndose éstos del intérprete [...] no hay quien promueva en los pueblos el castellano, antes bien tiene noticia de que les impresionan en que es falta de respeto hablar en castellano o se les castiga si lo hacen [...]" ${ }^{60}$

En síntesis, esta real cédula se refiere explícitamente a grandes e importantes temas subrayando los beneficios para el Rey, el Estado y la Iglesia de la castellanización de los indios ya que tomarían amor a la nación conquistadora, los obispos y su gobierno, ya que los pastores podrían gobernar y comunicarse con fluidez y sin obstáculos con su grey, el clero estaría más uniforme y se mejoraría su posición y nivel, pues estarían al frente de las parroquias los de más mérito, quitándole el "nocivo" monopolio de las lenguas que ostentaban los clérigos criollos. Al mismo tiempo, se desterrarían idolatrías de los indios, dado que el castellano brindaría exactitud en la explicación de la doctrina cristiana, se les haría más civilizados, y se fomentaría una mejor comunicación de los mismos con su entorno para el trato y el comercio sin intermediarios que solían engañarlos. También, se evitaría que los indios engañen o mientan a las autoridades, así como dar orden, homogeneidad y cohesión ante el des-

58 Tanck de Estrada, Dorothy, "Castellanización política y escuelas de indios", 725.

59 Tanck de Estrada, Dorothy, La Ilustración y la educación en la Nueva España, (México: SEP, 1985), 37-38.

60 Tanck de Estrada, Dorothy, La Ilustración y la educación, 38-39. 
orden que causaba la diversidad a ojos del Estado. Todo esto es pensado, como dice el rey, para sus dominios de toda América incluyendo Asia hispánica ${ }^{61}$.

Finalmente el rey Carlos III concluye su texto exhortando a las autoridades civiles y eclesiásticas, donde los arzobispos y obispos tenían un papel trascendental, a que:

"[...] guarde, cumplan y ejecuten y hagan guardar, cumplir y ejecutar puntual y efectivamente la enunciada mi Real resolución, disponiendo que desde luego se pongan en práctica y observen los medios que van expresados y ha propuesto el mencionado muy Rdo. Arzobispo de México, para que de una vez se llegue a conseguir el que se extingan los diferentes idiomas de que se usa en los mismos dominios, y sólo se hable castellano[... $]^{\prime 62}$

Ésta rotunda y singular orden es única para el entonces Imperio español por la fuerte convicción y aspiración de extinguir las lenguas de los indios tomando inspiración de las ideas del arzobispo Lorenzana.

Si bien esta cédula no se llevó a cabo a la práctica al pie de la letra, ni de manera uniforme, es indiscutible su marcada intencionalidad extintora de lo que no sea occidental, como lo eran las lenguas de los indios. Nunca antes un rey español había sido tan explícito y frontal en contra de ellas. Por todo esto, esta Real Cédula del 16 de abril de 1770 es considerada "[...] el epítome de las ideas autoritarias, eurocéntricas [...] de la política lingüística hacia las colonias españolas" "63, además, yo agregaría, de las ideas de unificación. Es decir, este momento constituye el clímax y el momento más álgido de la política lingüística unificadora en Nueva España y las indias, fomentado e inspirado en parte desde América con las labores de diferentes obispos y arzobispos que apoyaban esta causa.

\section{Conclusiones}

Para la segunda mitad de la centuria dieciochesca se reimpulsó con nuevos bríos la idea de expandir y posicionar a la lengua castellana como la única hablada en todo el imperio español, tanto así, que se habló de extinguir las numerosas lenguas nativas. Nunca antes un rey había emitido tal orden. Sin embargo, y como resulta evidente, ese deseo no se logró. Empero, lo que aquí me interesa subrayar es la marcada intencionalidad del monarca y de los más altos prelados de la Iglesia católica, la cual, por su intensidad, constituye el punto más álgido de las ideas de unificación lingüística, para

61 Tanck de Estrada, Dorothy La Ilustración y la educación, 44.

62 Tanck de Estrada, Dorothy La Ilustración y la educación, 37-45.

63 Tanck de Estrada, Dorothy "Castellanización política y escuelas de indios", 729. 
la época colonial. A nuestro juicio, las motivaciones para castellanizar, en la segunda mitad del siglo XVIII, son las siguientes: formar un bloque cultural ante las amenazas contra la paz del reino -tanto internas, como los motines de 1767, y externas como lo fueron conflictos con otras casas reinantes-, unificar, fomentar una comunicación con los indios sin intermediarios, integrar al indio a una sociedad en la que el trabajo era cuestión de suma importancia para la economía y para la cual sus lenguas eran consideradas como un obstáculo para poder entrar al sistema productivo, además de ser signo de "barbarie", siendo la lengua castellana la que lo alejaría de la segregación social y económica ${ }^{64}$, así, lo acercaría al progreso y felicidad tan deseados en la centuria dieciochesca, además de que eliminaría sus restos de "salvajismo". En suma, una castellanización integral, no solamente lingüística, que se apoyaría mucho en la educación de primeras letras, a cargo de un maestro, y en una catequesis en castellano por parte del cura. Esas intenciones castellanizadoras que venían desde España se nutrieron con las propuestas de importantes prelados de diócesis novohispanas, como el arzobispo Lorenzana, los obispos Fabián y Fuero y Sánchez de Tagle, cercanos colaboradores del rey en este ambicioso proyecto castellanizador abonado desde su trinchera. Esto nos ayuda a ver el papel activo que jugaba la Iglesia católica en la sociedad novohispana y en todo el Imperio español, contraria a la idea generalizada de que en solo jugaban roles de oración y liturgia al interior de las iglesias. Para el caso concreto de México, los planes pensados por el rey, el Estado español, los arzobispos y obispos de que se hablara mayoritariamente la lengua castellana, paradójicamente, tuvieron importantes avances con los gobiernos liberales del siglo XIX y los posrevolucionarios del siglo XX quienes impulsaron la educación y alfabetización de los indígenas. Llama mi atención que las connotaciones peyorativas con las que algunos de estos obispos se referían a las lenguas de los indios se mantienen hasta la fecha, doscientos cincuenta años después. Que estas líneas sirvan para repensar ese aspecto de nuestro pasado y darle dimensión a la lengua que hablamos millones de hispanohablantes y a las que estaban en estas tierras hasta antes de 1492.

\section{Bibliografía}

\section{Fuentes de consulta}

\section{Libros}

64 Iván Escamilla González, "El arzobispo Lorenzana: la Ilustración en el IV concilio de la Iglesia mexicana", en: Los concilios provinciales en Nueva España. Reflexiones e influencias, María del Pilar Martínez López-Cano, Francisco Javier Cervantes Bello (coords.), (México: Universidad Nacional Autónoma de México, Instituto de Investigaciones Históricas, Benemérita Universidad Autónoma de Puebla, Instituto de Ciencias Sociales y Humanidades, 2005), 131. 
Andrés-Gallego, José M., Antón Pazos, La Iglesia en la España contemporánea, 18001936, Tomo I, España: Encuentro Ediciones, 1999.

B. Buitrón, Juan, Apuntes para servir a la historia del arzobispado de Morelia, México: Imprenta Aldina, 1948.

Brading, David, Una Iglesia asediada: el obispado de Michoacán, 1749-1810, México: Fondo de Cultura Económica, 1994.

Castro Gutiérrez, Felipe, Nueva Ley y nuevo Rey: reformas borbónicas y rebelión popular en la Nueva España, México: El Colegio de Michoacán, Universidad Nacional Autónoma de México, Instituto de Investigaciones Históricas, 1996.

De Solano, Francisco (comp.), Documentos sobre política lingüística en Hispanoamérica (1492-1800), Madrid: Consejo Superior de Investigaciones Científicas, 1991.

Domínguez Ortiz, Antonio, Carlos III y la España de la Ilustración, Madrid: Altaya, 1996.

Feijoo, Benito Jerónimo, Teatro crítico universal, ó Discursos varios en todo género de materias, para desengaño de errores comunes escrito por el muy ilustre señor Don Fray Benito Gerónimo Feyjoó y Montenegro, Maestro General del Orden de San Benito del Consejo de Su Majestad, tomo primero, Madrid: D. Joaquín Ibarra, Real Compañía de Impresores y Libreros, 1778.

García Alcaraz, Agustín, La cuna ideológica de la independencia, Morelia: Fimax publicistas, 1971.

Geller, Ernest, Naciones y nacionalismo, España: Alianza editorial, 2001.

Guerrero, Omar, Las raíces borbónicas del estado mexicano, México: Universidad Nacional Autónoma de México, 1994.

Herr, Richard, España y la revolución del siglo XVIII, Madrid: Aguilar, 1975.

Jaramillo Magaña, Juvenal, Hacia una Iglesia beligerante: La gestión episcopal de Fray Antonio de San Miguel en Michoacán, 1784-1808, los proyectos ilustrados y las defensas canónicas, Zamora: El Colegio de Michoacán, 1996. 
León-Portilla, Miguel, Independencia, Reforma, Revolución, ¿y los indios qué?, México: Consejo Nacional para la Cultura y las Artes, Universidad Nacional Autónoma de México, Instituto de Investigaciones Históricas, 2011.

Menegus, Margarita, Mazín, Óscar et al, La secularización de las doctrinas de indios en la Nueva España. La pugna entre dos iglesias, México, UNAM, 2010.

Pérez Puente, Leticia, El concierto imposible: Los concilios provinciales en la disputa por las parroquias indígenas (México, 1555-1647), México, UNAM, 2010.

Quilis Morales, Antonio, Niederehe, Hans-Josef, The History of Linguistics in Spain, Ámsterdam: Jhon Benjamins Publishing Company, 1986.

Tanck de Estrada, Dorothy, La Ilustración y la educación en la Nueva España, México: SEP, 1985.

Triana y Antorveza, Humberto, Las lenguas indígenas en el ocaso del Imperio Español, Chile: Escuela de Filosofía Universal ARCIS, 1993.

\section{Capítulos de libros}

Escamilla González, Iván, "El arzobispo Lorenzana: la Ilustración en el IV concilio de la Iglesia mexicana." En: Los concilios provinciales en Nueva España. Reflexiones e influencias, coordinado por María del Pilar Martínez López-Cano, Francisco Javier Cervantes Bello, 123-144, México: Universidad Nacional Autónoma de México, Instituto de Investigaciones Históricas, Benemérita Universidad Autónoma de Puebla, Instituto de Ciencias Sociales y Humanidades, 2005 .

Pérez Puente, Leticia, "El obispo. Político de institución divina.” En: La Iglesia en la Nueva España. Problemas y perspectivas de investigación, coordinado por María del Pilar Martínez López-Cano, 151-184, México: Universidad Nacional Autónoma de México, Instituto de Investigaciones Históricas, 2010.

Tanck de Estrada, Dorothy, “El siglo de las luces.”En Independencia y Educación. Cultura cívica, educación indígena y literatura infantil, coordinado por Dorothy Thanck de Estrada, 117-145, México: El Colegio de México, 2013.

\section{Libros electrónicos}


Fabián y Fuero, Francisco, Carta pastoral del Ilustrísimo Señor Don Francisco Fabián y Fuero, Obispo de la Puebla de los Ángeles, Del consejo de su majestad, Barcelona: Thomas Piferrer Impresor del Rey Nuestro Señor, 1768. http://www. cervantesvirtual.com/obras/materia/cartas-pastorales-287 .

Fabián y Fuero, Francisco, Colección de Providencias Diocesanas de la Puebla de los Ángeles, Puebla: Imprenta del Real Seminario Palafoxiano, 1770. http://bdh. bne.es/bnesearch/Search.do?

Lorenzana, Francisco Antonio, Reglas Para que los Naturales de estos Reynos sean felices en lo espiritual, y temporal, México: 1768. http://bdh.bne.es/bnesearch/ detalle/bdh0000038591 .

Márquez Carrillo, Jesús, Política, Iglesia y modernidad en Puebla. Las ideas y proyectos reformistas del Obispo Francisco Fabián y Fuero, 1765-1773, México: Benemérita Universidad Autónoma de Puebla, Facultad de Filosofía y Letras, Primera Edición Digital, 2017. http://www.filosofia.buap.mx.

\section{Artículos de revista}

Asensio, Eugenio, "La lengua compañera del imperio. Historia de una idea de Nebrija en España y Portugal”, Filología Española 43.3 (1960): 359-413.

Malagón-Barceló, Javier, "La obra escrita de Lorenzana como arzobispo de México 1766-1772”, en: Historia Mexicana 3.23 (1974): 437-465.

Márquez Carrillo, Jesús, "Experiencia interior y política pastoral. El obispo Francisco Fabián y Fuero en Puebla 1765-1773", Graffylia: Revista de la Facultad de Filosofía y Letras 2 (2003): 103-111.

Mazín Gómez, Óscar, "Reorganización del clero secular novohispano en la segunda mitad del siglo XVIII", Relaciones 39-10 (1989): 69-86.

Mazín, Óscar, "Secularización de parroquias en el antiguo Michoacán”, Relaciones 26-4 (1986): 23-34.

Pérez Puente, Leticia, "La creación de las cátedras públicas de lenguas indígenas y la secularización parroquial”, Estudios de Historia Novohispana, 41 (2009): 45-78. 
Pietschmann, Horst, “Consideraciones en torno al protoliberalismo, reformas borbónicas y revolución. La Nueva España en el último tercio del siglo XVIII", Historia Mexicana, 41-2 (1991): 167-205.

Tanck de Estrada, Dorothy, "Castellanización, política y escuelas de indios en el Arzobispado de México a mediados del siglo XVIII", Historia Mexicana, 38-4 (1989): 701-741.

\section{Artículos de revista electrónica}

Aranda Juárez, Blanca Estela, "La educación en los religiosos agustinos del siglo XVII”, Destiempos 18 (2009). Consultado el día 3 de mayo de 2018, http:// www.destiempos.com/n18/aranda.pdf

Cedeño Peguero, María Guadalupe, "Las escuelas parroquiales del obispado de Michoacán, Nueva España, Reforma educativa de Gerónimo López Llergo, 176517670", Heurística Revista Digital de Historia de la Educación 17 (2014), consultado el día 15 de mayo de 2018, https://dialnet.unirioja.es/servlet/revista? codigo $=11336$

López Sarrelange, Delfina, "Población indígena de la Nueva España en el siglo XVIII", Historia Mexicana 4 (1968). Consultado el 22 de julio del 2018, http:// historiamexicana.colmex.mx/index.php/RHM/article/view/984

Tesis

Cedeño Peguero, María Guadalupe, "Educación, iglesia y estado. De las escuelas de castellano a las de caja de comunidad. Tres momentos de la educación elemental indígena en el Michoacán colonial. Siglos XVII y XVIII", Tesis de doctorado, UNAM, 2011.

Cruz Peralta, Clemente, "Entre la disciplina eclesiástica y la reforma de las costumbres: Visitas pastorales de Francisco Antonio Lorenzana a la arquidiócesis de México, 1767-1769", Tesis de maestría, Universidad Nacional Autónoma de México, Facultad de Filosofía y Letras, Instituto de Investigaciones Históricas, 2016. 